\title{
THE POLYCHROME SINOPIA OF ROMAN MOSAIC AT LOD (ISRAEL): PIGMENTS CHARACTERIZATION AND MICROSTRATIGRAPHIC STUDY
}

\author{
R. Piovesan a, *, L. Maritan a, J. Neguer b \\ a Department of Geosciences, University of Padova, Via Gradenigo 6, 35131 Padova, Italy - (rebecca.piovesan, \\ lara.maritan)@unipd.it \\ b Art Conservation Department, Israel Antiquities Authority - neguer@yahoo.com
}

KEY WORDS: Mosaic, Policrome Sinopia, Pigment analysis, Microstratigraphy, Painting techniques, Roman Times

\begin{abstract}
:
This paper presents the results of the archaeometric study on the pigments and the painting techniques used to produce the polichrome sinopia found under the tesserae of the Roman mosaic at Lod (Israel). The red, yellow, green and black paints, laying on the sovranucleus of the preparation mortar under the mosaic, were studied by polarised light microscopy on disperse pigments (PLM), reflected light microscopy (RLM), scanning electron microscopy (SEM) and X-ray powder diffraction (XRPD). The palette comprises red and yellow ochre, cinnabar, green earth and carbon black. The microstratigraphic analysis shows the presence of a carbonation layer including the pigment particles on the top of the mortars, indicating that the pigments were laid on a fresh mortar, according to a fresco technique.
\end{abstract}

\section{INTRODUCTION}

The Roman mosaic from Lod (formerly Lydda, $20 \mathrm{~km}$ southeast Tel Aviv, Israel) is one of the most beautiful and famous pavements of the Roman Empire. It was fortuitously discovered in 1996 and excavated by the Israel Antiquities Authority (Avissar, 1998).

The mosaic, representing both real and mythological animals (Figure 1), is constituted by 3 very well preserved floors, for a total area of $150 \mathrm{~m}^{2}$. It is dated to about $300 \mathrm{AD}$ and probably belongs to a large and important Roman villa (Haddad and Avissar, 2003). The ichnography of the mosaic suggests that the owner of the villa was a rich merchant who probably reached his position thanks to maritime trade.

After the detachment performed in the 2009 by the Art Conservation Department of the Israel Antiquities Authority, a extraordinary polychrome sinopia (an underpainting) was discovered under one of the most evocative scene of the mosaic, the marine representation of fishes and vessels (Figure 2).

It worth noting that the term sinopia normally refers to an underpainting realised using a red ochre, originally from Sinop on the Black Sea (Turkey), to make a preparation draw for a fresco, generally executed on the finer mortar layer, the arriccio. This technique was largely used until the sixteen century, when it was gradually substituted by other preparation techniques, such as graffito and pounce. The adoption of a sinopia in the production of a mosaic was typical of the Greek word and less frequently used in the Roman mosaics. Besides, the Greek artisans used only one pigment to draw the sketch on which apply the tesserae (mainly red ochre or carbon black), and polychrome sinopiae have never been attested before. For all these reasons, the finding of a polychrome sinopia, a red, green, yellow and black paint under the marine scene of the mosaic from Lod is absolutely unique in the history of art.

This study mainly aims to characterize the pigments adopted to prepare the rare polychrome sinopia discovered under the extraordinary marine-scene panel of the Lod mosaic, as well as to define the microstratigraphy of the paint.

\footnotetext{
* Corresponding author.
}

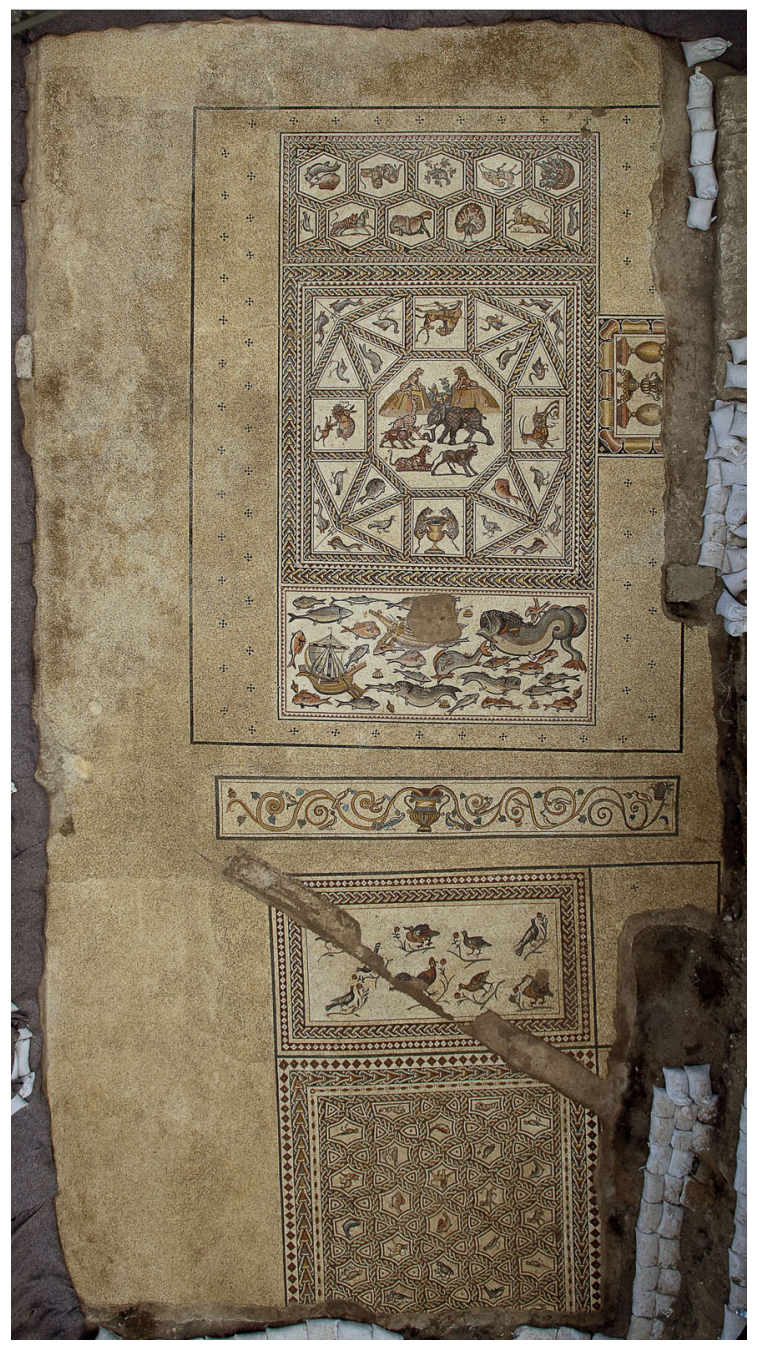

Figure 1. The Lod mosaic 


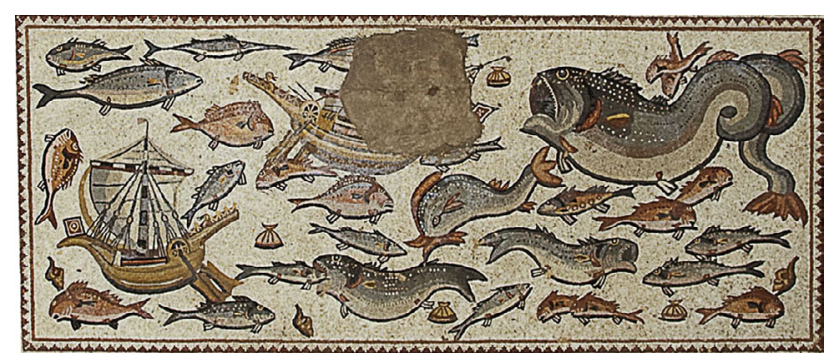

Figure 2. Detail of the marine-scene panel

These will supply information on the painting technique adopted to paint the sketch, and in particular to verify whether it was realised as a fresco. Indeed macroscopic analysis of the mortar shows the presence of joints in the preparation layer (sovranucleus), indicating daily applications of mortar (giornate), and suggesting the use of this technique.

All these aspects will indicate the technological knowledge owned by the masters who made the mosaic.

\section{MATERIALS AND METHODS}

A set of 8 fragments of sovranucleus bearing four different colours (red, yellow, green, black) was selected for this study (Figure 3).
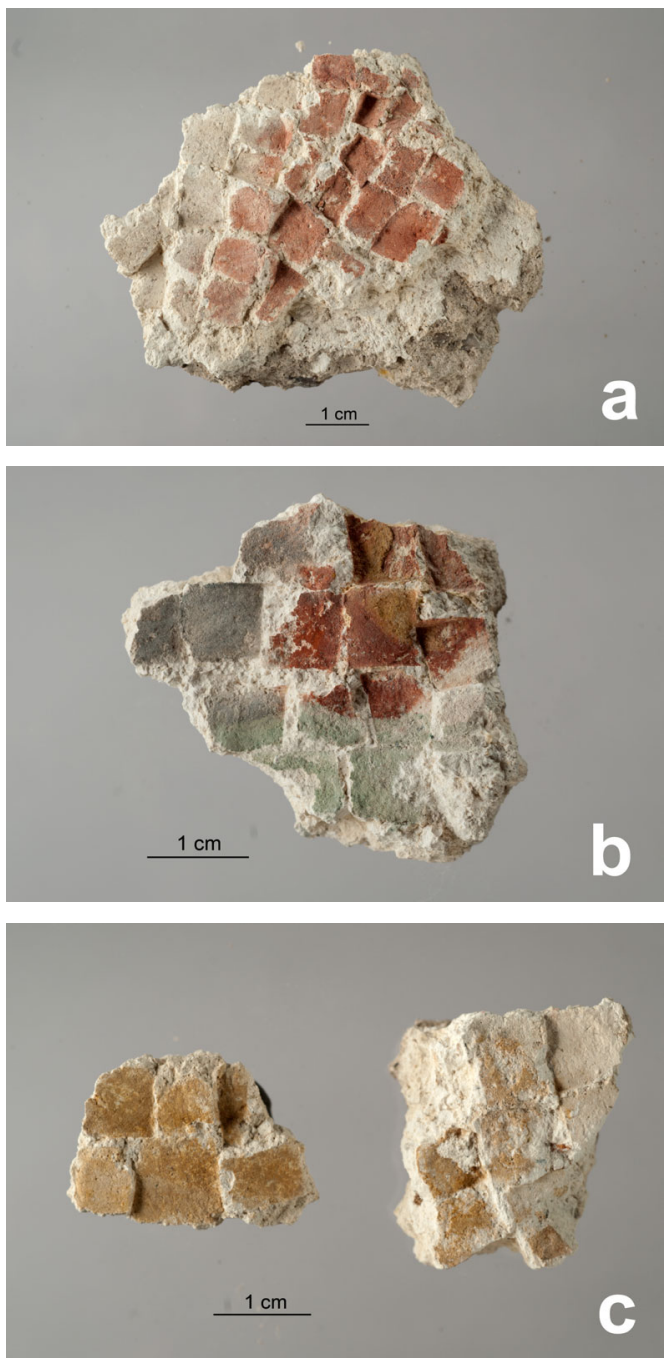
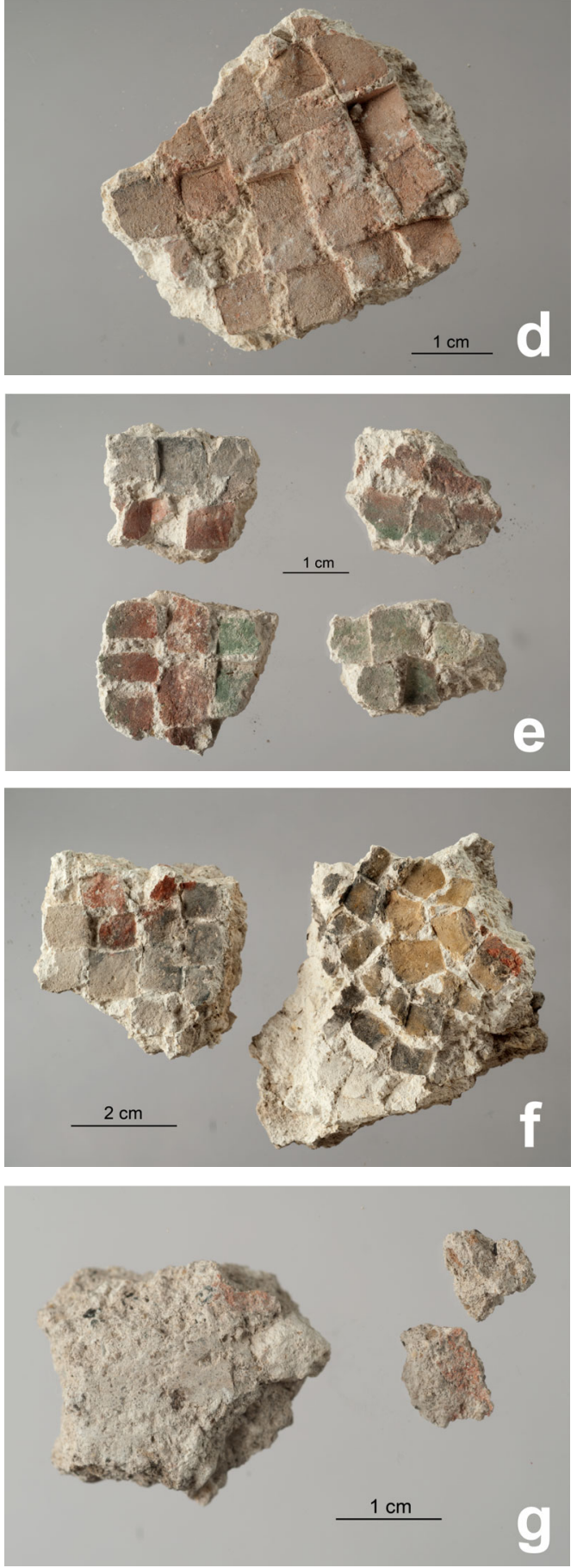

Figure 3. Hand specimens of the painted sovranucleus: a) sample 1- red; b) sample 2 - red, yellow, green and black; c) sample 3 - yellow; d) sample 4 - pale red; e) sample 5 - red, green and black; f) sample 6 (on the left) - red and black; and 7 (on the right) - red, yellow and black; g) sample 8 - trace of red pigment in a small track

Macroscopic observations indicates the classical stratigraphy of the Roman mosaics, formed by a thick preparation layer of gravel and clay used to level the ground roughness and to form a solid base for the floor, covered by a rudus, a layer of rough mortar, in turn covered by a sovranucleus, a layer of finer mortar on which the sinopia was painted, and the tesserae (Figure 4). 


\section{RESULTS AND DISCUSSION}

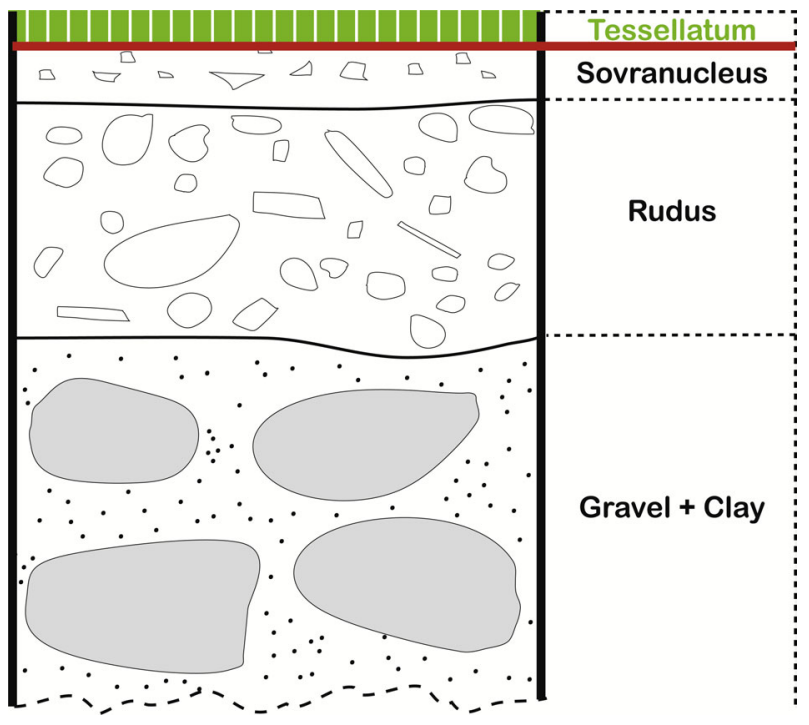

Figure 4. Stratigraphy of the Lod mosaic floor. The red line shows the position of the sinopia painting

\begin{tabular}{cccccc}
\hline N. & Sample & PLM & RLM & $\begin{array}{c}\text { SEM- } \\
\text { EDS }\end{array}$ & XRPD \\
\hline 1 & 1R & $\mathrm{X}$ & $\mathrm{X}$ & $\mathrm{X}$ & \\
\hline 2 & 2R & $\mathrm{X}$ & $\mathrm{X}$ & $\mathrm{X}$ & $\mathrm{X}$ \\
\hline 3 & 2G & $\mathrm{X}$ & $\mathrm{X}$ & $\mathrm{X}$ & \\
\hline 4 & 2Y & $\mathrm{X}$ & $\mathrm{X}$ & $\mathrm{X}$ & \\
\hline 5 & 2B & $\mathrm{X}$ & $\mathrm{X}$ & $\mathrm{X}$ & \\
\hline 6 & 3Y & $\mathrm{X}$ & $\mathrm{X}$ & $\mathrm{X}$ & $\mathrm{X}$ \\
\hline 7 & 4R & $\mathrm{X}$ & $\mathrm{X}$ & $\mathrm{X}$ & \\
\hline 8 & 5R & $\mathrm{X}$ & $\mathrm{X}$ & $\mathrm{X}$ & \\
\hline 9 & 5B & $\mathrm{X}$ & $\mathrm{X}$ & $\mathrm{X}$ & \\
\hline 10 & $5 \mathrm{G}$ & $\mathrm{X}$ & $\mathrm{X}$ & $\mathrm{X}$ & $\mathrm{X}$ \\
\hline 11 & 6R & $\mathrm{X}$ & $\mathrm{X}$ & $\mathrm{X}$ & \\
\hline 12 & $6 \mathrm{~B}$ & $\mathrm{X}$ & $\mathrm{X}$ & $\mathrm{X}$ & \\
\hline 13 & 7R & $\mathrm{X}$ & $\mathrm{X}$ & $\mathrm{X}$ & \\
\hline 14 & $7 \mathrm{Y}$ & $\mathrm{X}$ & $\mathrm{X}$ & $\mathrm{X}$ & \\
\hline 15 & 7B & $\mathrm{X}$ & $\mathrm{X}$ & $\mathrm{X}$ & \\
\hline 16 & 8R & $\mathrm{X}$ & & & \\
\hline & & & & & \\
\hline
\end{tabular}

Table 1. List of samples and analyses performed on them. The sample labels are composed as follow: number.letter, indicating the number of sample (according to figure 3 ) and the colour of the paint (R: red, G: green, Y: yellow, B: black), respectively

Samples were studied according to a multianalytical approach, consisting on the combination of microscopic, microstratigraphic, microchemical and mineralogical analysis (Table 1). More in detail, all the fragments were studied by:

i) optical microscopy in reflected light (RLM) on cross sections, in order to accurately define the microstratigraphy;

ii) optical microscopy in transmitted light on pigment dispersion (PLM), to identify the type of pigments;

iii) scanning electron microscopy coupled with an energy dispersive spectrometer (SEM-EDS) on cross sections for the identification of the pigments and to verify the microstratigraphy;

iv) X-ray powder diffraction (XRPD) to define the mineralogical composition of the pigments.

\subsection{Microstratigraphy}

Most of the analyzed samples are constituted by a very simple microstratigraphy, such as that shown in Figure 5a, made by the following sequence of layers:

A: white plaster layer (sovranucleus);

$\mathrm{B}$ : painting layer.
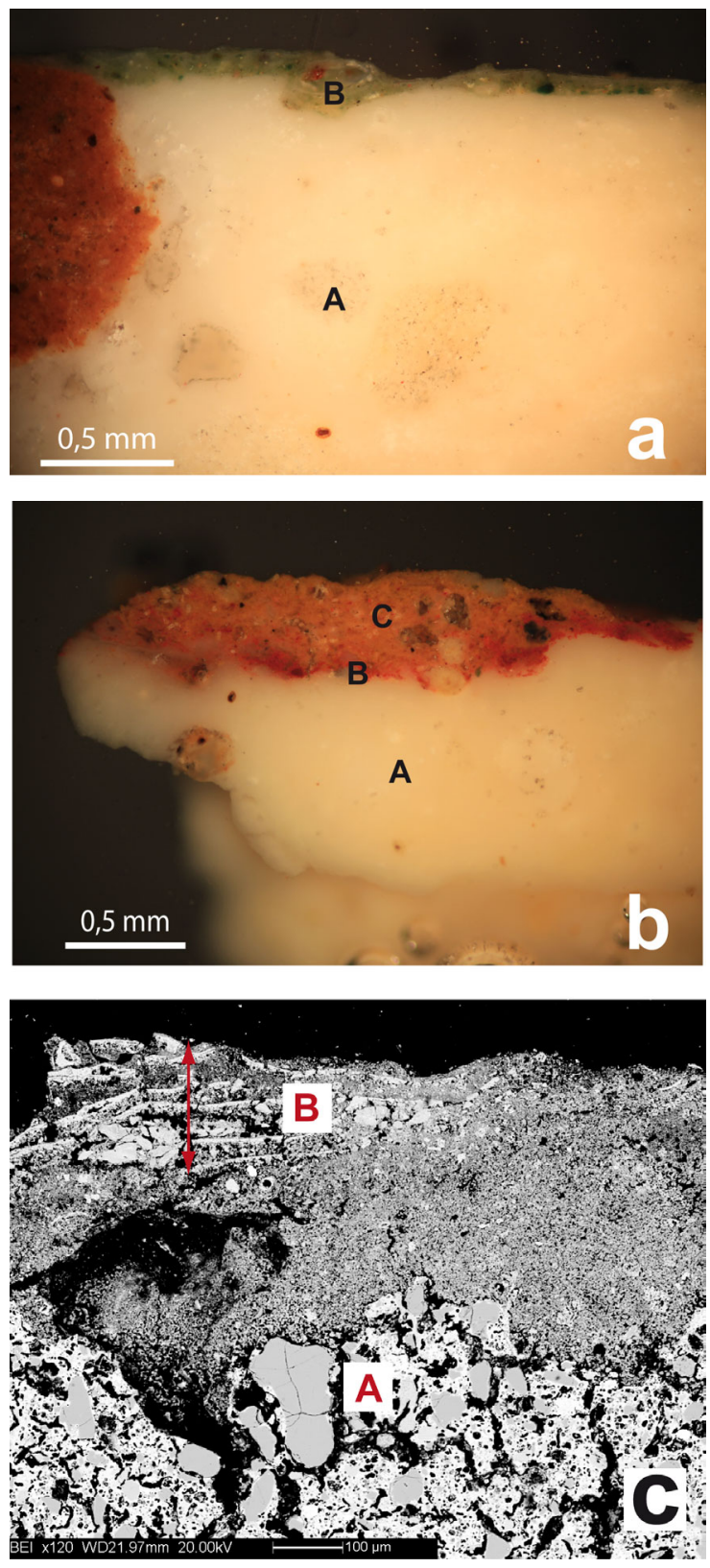

Figure 5. a) RLM micrograph of the cross section of sample $2 \mathrm{G}$ with only two layers (A: sovranucleus; B: painting); b) RLM micrograph of the cross section of sample $2 \mathrm{Y}$, where two painting layer are present (layer B and C); c) SEM-BSE image of sample $5 \mathrm{G}$ with several carbonation layers on the surface

Among the studied samples, some exceptions to this simple stratigraphy were find. The first one is the sample $2 \mathrm{Y}$, where two painted layers are present. This anomaly is due to a partial 
overlapping of a yellow area (layer C) on a red one (layer B) (Figure 5b).

Another exception is the sample 5G, which shows a thicker green layer, the back scattered electron image (SEM-BSE) of which shows that it is formed by several layers similar in composition (Figure 5c). Moreover, the presence of at least two carbonation layers (arrows in Figure 5c) indicates that the artist waited several hours between one brushstroke and another, during which the mortar underwent a gradual hardening.

\subsection{Painting layers}

SEM analysis on the paintings shows a thin white layer on the surface of each sample (Figure 6), incorporating the pigment particles. This, as described in Piovesan et al. (2012), is the result of the carbonation process occurred on the surface of a mortar during the hardening, and clearly indicating that the painting was realized following the fresco technique. Therefore the particles of pigments were spread on the fresh mortar of the sovranucleus only diluted in water.

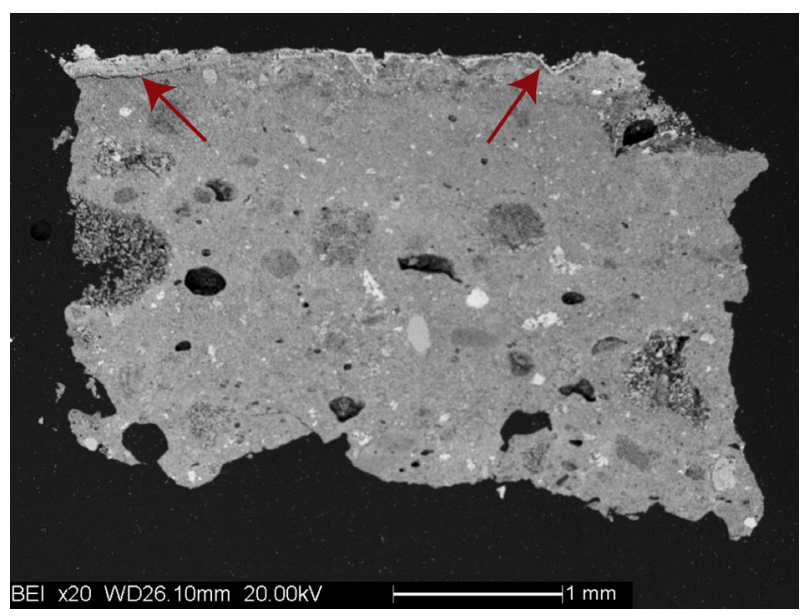

Figure 6. SEM-BSE image of sample 4R: the red arrows show the typical carbonation layer at the surface, including the pigment particles

\subsection{Pigments}

PLM, SEM-EDS and XRPD analyses indicated that each colour of the sinopia is composed by a single pigments, with the exception of the red one, and that 5 different pigments were identified.

The red colours are mainly due to the use of red ochre. This pigment is mostly formed by hematite, which is characterised at the PLM by interference colours typically masked by the strong body colour (Figure 7a). The size of these particles ranges between around 50 and $200 \mu \mathrm{m}$.

In some cases the red colour of the sinopia was obtained using, in addition to the red ochre, a very fine-grained pigment, few microns in size, often occurring in dense aggregates at the sample surface (white particles in the SEM-BSE images of Figure 8a), the microchemical composition of which is very high in $\mathrm{Hg}$, indicating that is formed by cinnabar (Figure $8 \mathrm{~b}$ ). This pigment was not recognized under PLM and RLM, probably for the extremely small dimension of the particles.
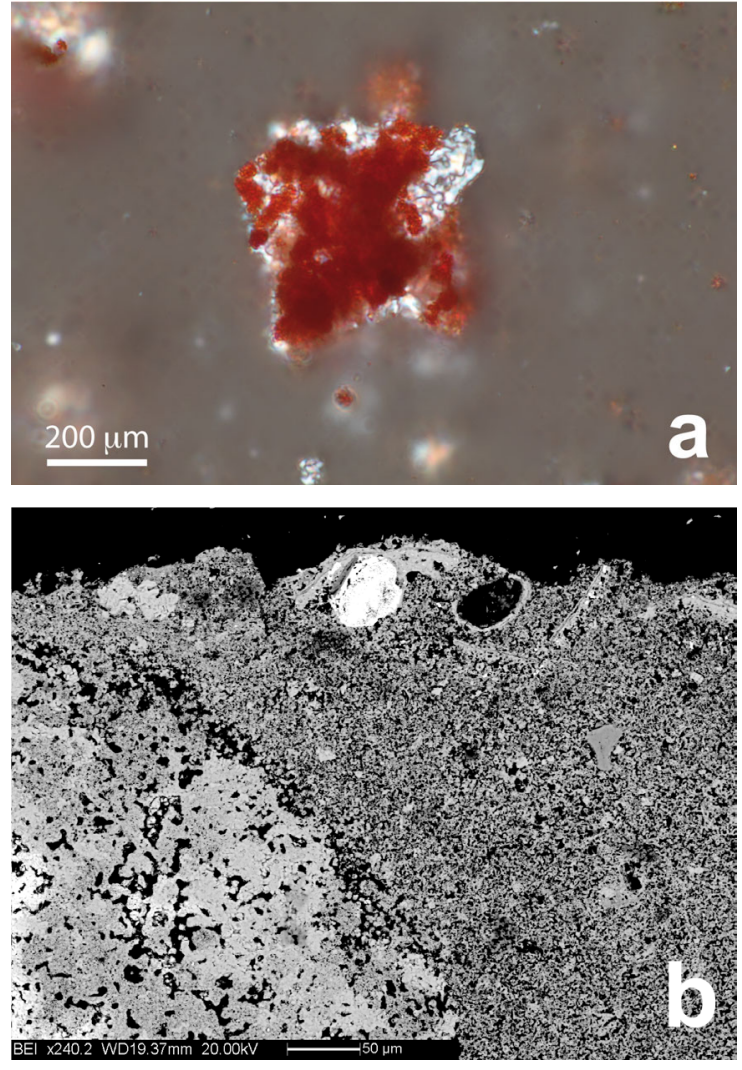

Figure 7. a) PLM micrograph of red ochre particles (plain polars); b) SEM-BSE image showing sparkling white particles at the sample surface, very rich in Fe in the EDS analysis.
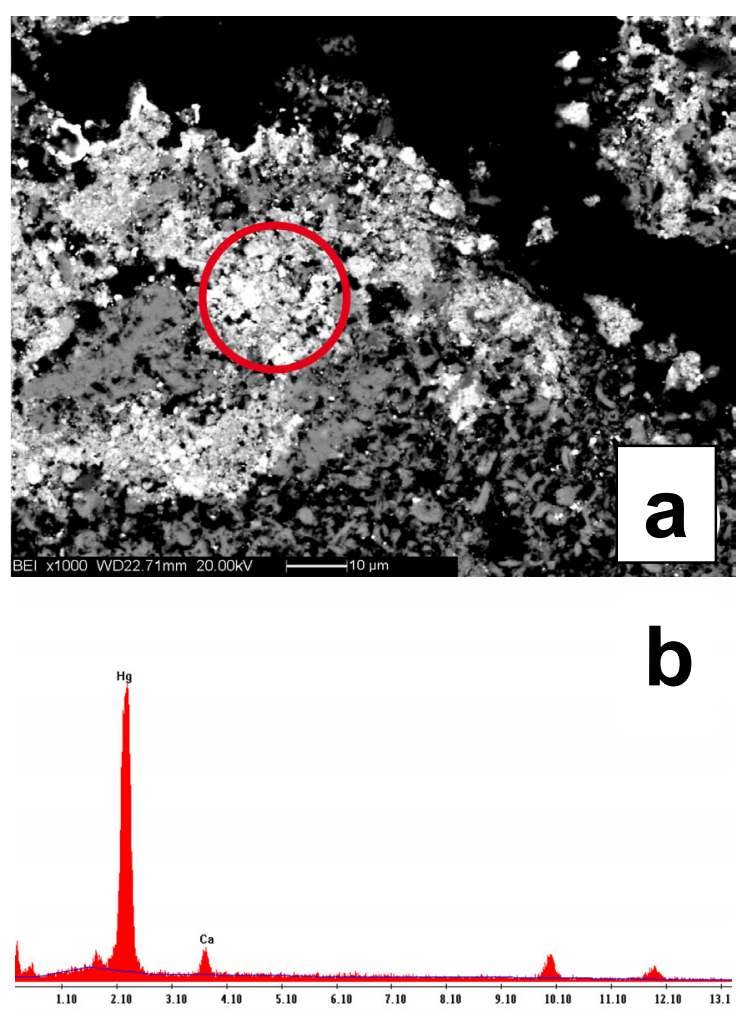

Figure 8. a) SEM-BSE image of very fine particles (in the white circle) showing high contents of $\mathrm{Hg}(\mathrm{b})$ 
The yellow colour was obtained using a yellow ochre, mainly composed by goethite (Figure 9), characterised, when observed under PLM in pigment dispersion, by interference colours typically masked by the strong body colour (Figure 9a).
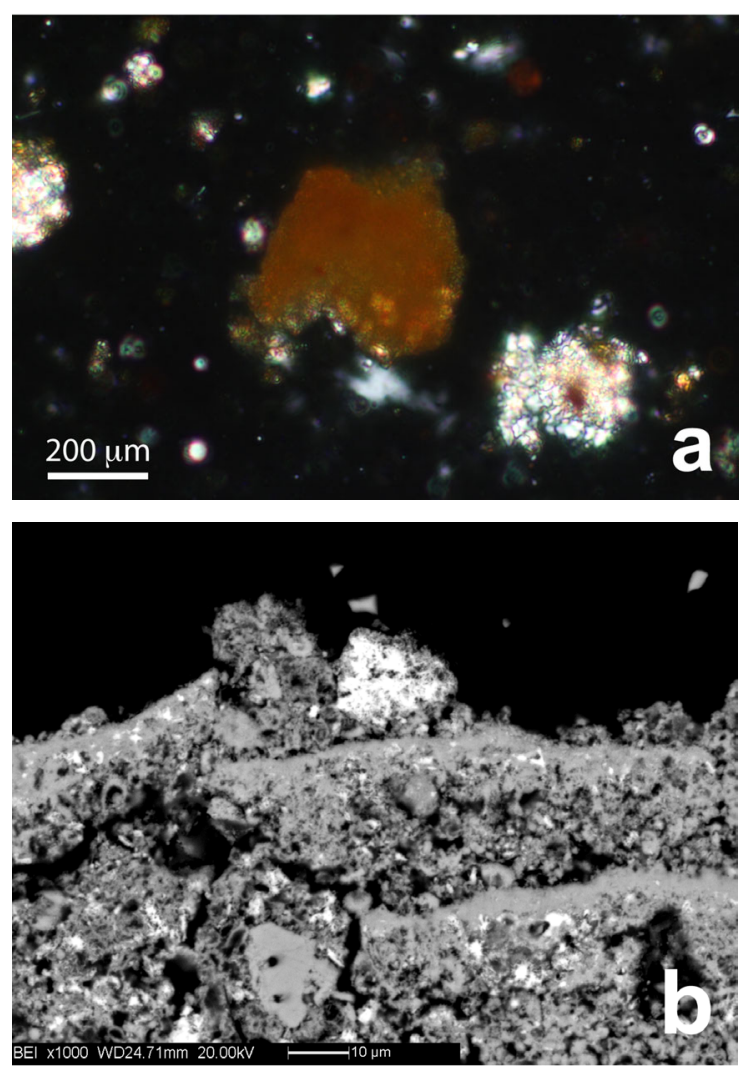

Figure 9. a) PLM micrograph of yellow ochre particles (cross polars); b) SEM-BSE image showing sparkling white particles at the sample surface, very rich in Fe in the EDS analysis

The green pigment is composed by green earth, formed by subrounded particles, some tens to hundreds microns in size (Figure 10a). This type of pigment may be composed by either glauconite or celadonite. The distinction among these phases is generally difficult since both have very similar XRPD patters, with peaks at the same 2Theta values (Figure 10b). The occurrence of micro-foraminifera shells associated with the pigment particles at the sample surface, as shown in the SEMBSE images (Figure 10c), indicates that the green earth used for the sinopia of the Lod mosaic derives from seashore deposits, and it is formed by glauconite.

Finally, the black colour was obtained using a carbon black pigment, in which the carbon particles show the characteristic black and opaque colour and occur with irregular shape (Figure 11a). In many cases traces of the cellular structure are well preserved (Figure $11 \mathrm{~b}$ at the centre). Moreover, this pigment is associated to the presence of spheritical particles of glass, showing degassing bubbles (Figure 11b), probably produced for the melting of soil particles during the combustion of vegetal remains (wood or chaff) for obtaining the carbon black.
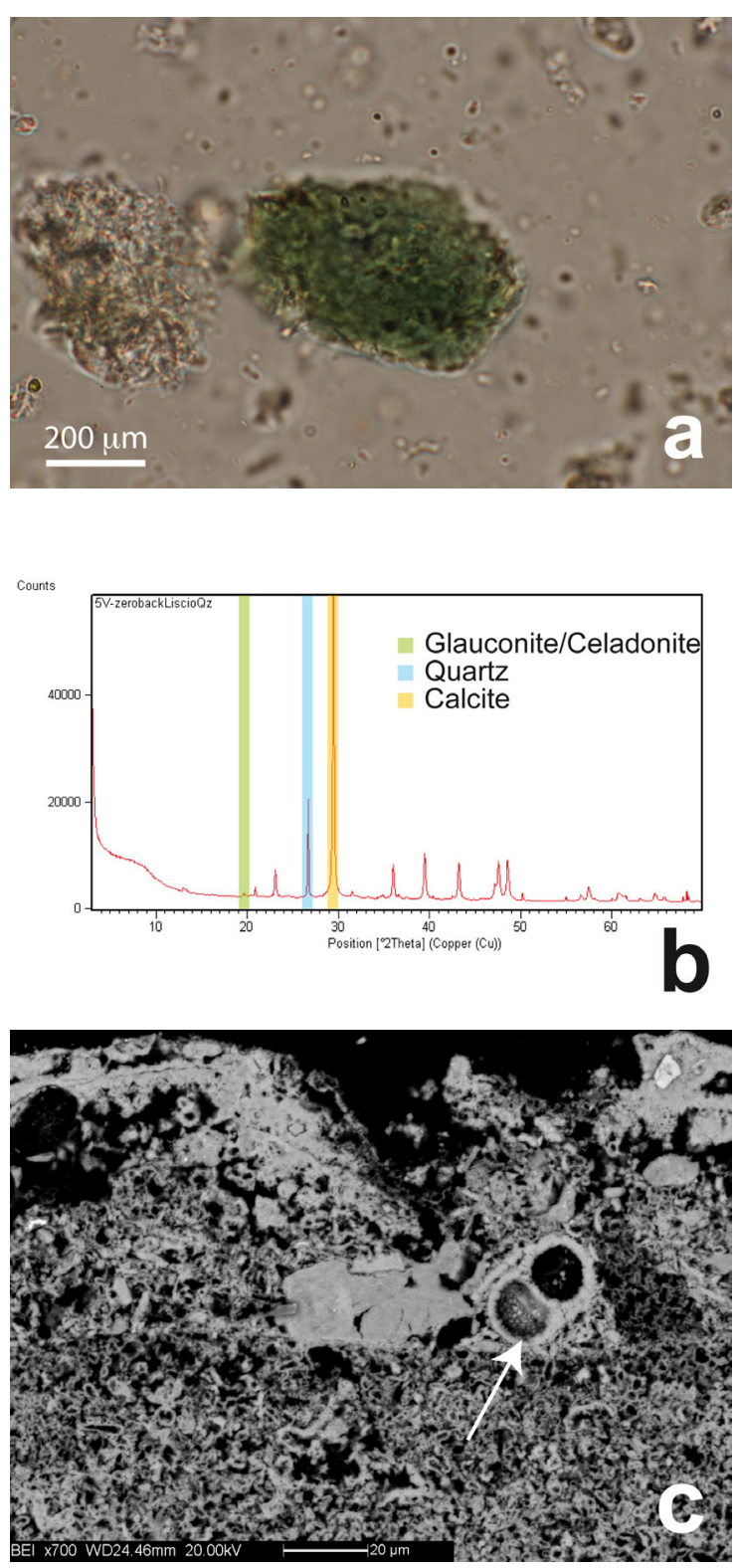

Figure 10. a) PLM micrograph of pale green rounded particles (plain polars); b) XRPD pattern; c) SEM-BSE image of green earth particles associated with shells of micro-foraminifera on the sample surface suggesting that the green earth comes from seashore deposits and is formed by glauconite

\section{CONCLUSIONS}

The results obtained by this multianalytical study of the polychrome sinopia discovered under the marine scene of the Lod mosaic show a composition of the pigments used and a structure more complex than expected.

Starting from the colour palette, the use of five different pigments indicates the need of the artists who realised the mosaic to have a very detail paint to use as a base when executing the mosaic itself. This would respond to the commissioner requirement to have a very high quality mosaic, probably representing his main activities. The pigments used, and in particular the red and yellow ochre, the green earth and the carbon black, are very common pigments, easily available. 

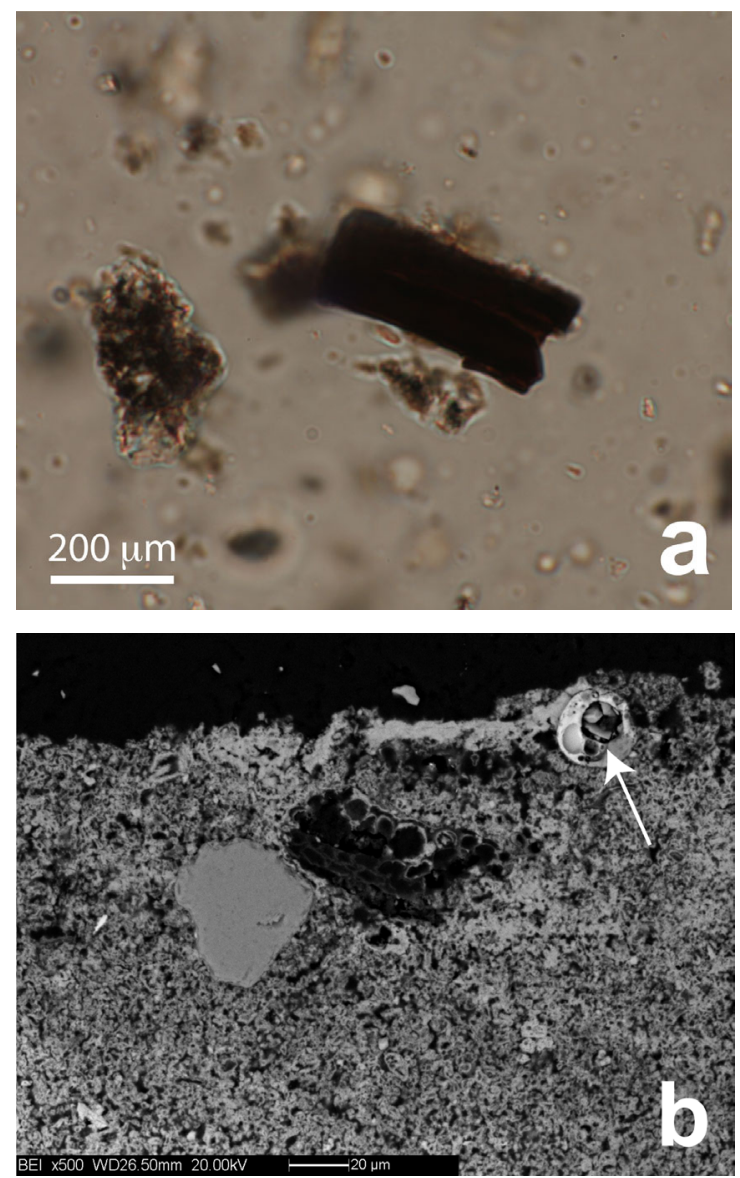

Figure 11. PLM micrograph of black and opaque particle showing regular shape and traces of cellular structure (plain polars); b) SEM-BSE images showing well preserved cellular structure and glass particles (white arrow) probably derived from the combustion process

The cinnabar represent an important exception, since it is an unusual pigment to produce a draw that would be covered by the mosaic tesserae, due to its high value and cost. Although found occasionally, the occurrence of the cinnabar indicates that the artist who realised the sinopia had important skill in the painting decorations, so that he has this precious pigment among his colour palette.

The presence of a carbonation layer on the top of samples, including the pigment particles, indicates that the pigments were laid on a fresh mortar, according to a fresco paint technique.

All these pieces of information indicate that the extraordinary and unique, for that period, polychrome sinopia found under the Lod mosaic attests the wealth of the commissioner as well as his desire of realising a superb and unique piece of art probably to celebrate his success in the marine trades.

During the conservation of the mosaic three panels with sinopia were successfully divided from the backing of the mosaic. The extremely complicated operation of detaching the sopranucleus from the lime bed without to damage the paint layer was accomplished in the laboratory. The panels of painted plaster were conserved using the techniques for wall paintings conservation according to the data from this research. In the light of the consideration about the painting technique the conservation problems were resolved using the knowledge for frescoes conservation and consolidation. The exhibition panels were executed using the systems for wall painting conservation: honeycomb panels with sacrificial layer with the painted plaster applied using lime mortar.
The whole process of conservation of the Lod mosaic can be followed on www.lodmosaic.org. In this moment part of the Lod mosaic and one of the panels with sinopia are exposed at Columbus MUseum of Art, Columbus, Ohio, USA. The entire mosaic with all the other discoveries from the archaeological site will be exposed at the Shelby White and Leon Levy Archaeological Centre (under construction) in the city of Lod, Israel.

\section{REFERENCES}

Avissar, M., 1998. Lod - A Mosaic Floor. Excavations and Surveys in Israel 17.

Haddad, E., Avissar, M., 2003. A Suggested Reconstruction of one of the Merchant Ships on the Mosaic Floor in Lod (Lydda) Israel. The International Journal of Nautical Archaeology 32 (1), pp. 73-77.

Piovesan, R., Mazzoli, C., Maritan, L., Cornale, P., 2012. Fresco and mezzofresco: experimental study and objective distinguishing criteria for the identification of the painting technique. Archaeometry 54 (4), pp. 723-736. 